\title{
Usia Dan Jenis Stroke Berpengaruh Terhadap Derajat Insomnia Pada Pasien Stroke
}

\author{
Eny Erlinda Widiaastuti \\ Jurusan Keperawatan, Poltekkes Kemenkes Pangkalpinang, Indonesia \\ Email Korespondensi: enyerlinda.widyaastuti@gmail.com
}

\begin{abstract}
Abstrak
Insomnia menyebabkan pemulihan pasien stroke tidak optimal pada masa pemulihan dan rehabilitasi. Oleh karena itu perlu dilakukan suatu upaya untuk mengetahui hal-hal yang mempengaruhi derajat insomnia pada pasien stroke. Penelitian ini bertujuan untuk mengetahui pengaruh usia, jenis stroke dan riwayat insomnia sebelum sakit terhadap derajat insomnia pada pasien stroke di RSUD Pangkalpinang dan Sungailiat. Penelitian ini menggunakan desain cross sectional without control dengan melibatkan 38 orang responden. Pemilihan responden penelitian dengan teknik consequtive sampling. Hasil analisis jenis stroke terhadap derajat insomnia pasien stroke didapatkan bahwa ada perbedaan proporsi kejadian derajat insomnia antara pasien stroke iskemik dan perdarahan $(p=0,000$ dan $\alpha=5 \%)$ dan hasil analisis rerata usia menurut derajat insomnia didapatkan adanya perbedaan rerata usia pada derajat insomnia $(p=0,003$ dan $\alpha=5 \%)$.
\end{abstract}

Kata kunci: Insomnia, Stroke

\section{Age And Type Of Stroke Affect The Degree Of Insomnia In Stroke Patients}

\begin{abstract}
Insomnia cause unoptimal recovery and rehabilitation stroke patience. Therefore it's needed effort to explore everything that could influence severity of insomnia to stroke patience. This research aiming to find out influence age, kind of stroke, and insomnia history before get sick to stroke patience on RSUD Pangkalpinang and Sungailiat. This researche designed by cross sectional without control with 30 respondent. Respondent election by consequtive sampling. Analysis results showed there's different proportional incident for kind of stroke to insomnia severity between ischemic stroke patience and haemoraghic $(\mathrm{p}=0,000$ and $\alpha=5 \%)$ and There's different average between age according to insomnia severity $(p=0,003$ dan $\alpha=5 \%)$.
\end{abstract}

Keywords: Insomnia, Stroke

\section{PENDAHULUAN}

Stroke memberikan dampak luas terhadap penderitanya. Manifestasi klinis yang muncul dari stroke dapat beragam dan dipengaruhi oleh pembuluh darah otak yang mengalami masalah penyumbatan atau ruptur. Selain itu, pemulihan pasien stroke berbeda dengan pasien lainnya karena neuron tidak memiliki sifat regenerasi sel seperti sel tubuh lainnya. Oleh karena itu, masa pemulihan pasien stroke harus dimanfaatkan secara optimal untuk dapat mencegah berbagai komplikasi yang muncul sebagai masalah baru pada pasien stroke.
Tidur memiliki fungsi fisiologis tubuh yang berhubungan dengan pemulihan tubuh. Tidur menjadi cara tubuh mengembalikan tingkat aktivitas dan keseimbangan normal tubuh (Kozier \& Erb's, 2008). Hipotesis "restorasi dan pemulihan" menyebutkan bahwa salah satu fungsi fisiologis tidur adalah mengembalikan kondisi tubuh ke tingkat normal dengan memulihkan energi dan sel- sel jaringan rusak kecuali otak yang bersifat nonregeneratif (Sheerwood, 2009). Oleh karena itu, gangguan tidur dapat menyebabkan berbagai masalah seperti penurunan berbagai fungsi seperti memori, daya tahan tubuh, konsentrasi, sampai produktivitas seseorang 
(Sasmita Das et al, 2014). Pada akhirnya, gangguan tidur dapat menyebabkan penurunan produktivitas dan kualitas hidup seseorang (Kozier \& Erb's, 2008).

Pemaparan mengenai fungsi tidur di atas memberikan gambaran dampak terhadap pemulihan pasien stroke tidak optimal. Oleh karena itu, pengenalan terhadap masalah tidur pada pasien stroke harus dilakukan misalnya masalah insomnia. Insomnia dapat bersifat akut dan kronik. Pada pasien stroke, insomnia dapat akut karena muncul setelah stroke terjadi dan bila tidak mendapatkan penanganan yang tepat dapat menjadi kronik. Insomnia akut terjadi bila gangguan tidur terjadi beberapa hari sampai minggu. Bila insomnia terus berlanjut mencapai bulan maka dikatakan sebagai insomnia kronik. International Classification of Sleep Disorder (ICSD) memberikan batas waktu insomnia akut meliputi beberapa hari sampai empat minggu, insomnia sub akut meliputi empat minggu sampai kurang dari enam bulan sedangkan insomnia kronik bila melebihi enam bulan. Kozier and Erb's (2008) menyebutkan bahwa istilah insomnia kronik intermiten yang menggambarkan kondisi insomnia yang terjadi beberapa malam kemudian diikuti tidur adekuat beberapa malam.

Insomnia yang terjadi pada pasien stroke dapat merupakan gejala yang muncul akibat adanya bagian tertentu otak yang berkaitan dengan fungsi fisiologis tidur yang terganggu. Oleh karena itu, insomnia pada pasien stroke perlu dikaji dan dikenali secara dini untuk dapat mencegah dampak yang merugikan bagi pasien.

Masalah penelitian ini adalah bagaimana hubungan usia, jenis stroke dan riwayat insomnia terhadap derajat insomnia pada pasien stroke di RSUD Depati Hamzah Pangkalpinang dan RSUD Depati Bahrin Sungailiat.tahun 2017. Penelitina ini bertujuan untuk Mengetahui hubungan antara usia, jenis stroke dan riwayat insomnia terhadap derajat insomnia pada pasien stroke.

\section{METODE}

Jenis penelitian ini kuantitatif dengan pendektan cros sectional. Penelitian ini hanya melibatkan dua kelompok yang dibedakan berdasarkan jenis stroke. Peneliti kemudian melakukan pengukuran derajat insomnia menggunakan kuesioner (Insomnia severity Index).

Penelitian ini dilakukan di RSUD Depati Hamzah Pangkalpinang dan RSUD Depati Bahrin pada Bulan September s.d Oktober tahun 2017. Populasi penelitian ini adalah semua penderita stroke di RSUD Depati Hamzah Pangkalpinang dan RSUD Depati Bahrin.

Penelitian ini merupakan penelitian yang bertujuan menguji hipotesis beda rata-rata derajat insomnia kelompok independen. Penelitian yang dilakukan oleh Sterr et al (2008) mengenai masalah gangguan tidur pada pasien stroke menunjukkan bahwa standar deviasi $(\sigma)=2,72$ dan nilai perbedaan rata-rata sebesar 1,6 maka didapatkan sample penelitian untuk penelitian ini adalah 16,7.

Dengan demikian besar sampel setiap kelompok adalah 17 orang. Peneliti menyiapkan $10 \%$ tambahan partisipan untuk mengantisipasi kemungkinan drop out selama proses penelitian maka jumlah responden yang akan dilibatkan dalam penelitian ini sebanyak 37 responden. jumlah ini ganjil sehingga ketika dibagi dua menjadi 18,5 responden sehingga dibulatkan menjadi 38 responden.

Pengumpulan data dilakukan dengan cara mencari responden yang memenuhi kriteria yaitu pasien stroke yang mengalami masalah insomnia. Instrumen yang digunakan dalam penelitian ini adalah indek derajat insomnia (Insomnia Severity Indextz) yang diberikan kepada setiap responden. Responden terlebih dahulu diberikan penjelasan mengenai tujuan dan persetujuan penelitian kemudian dilanjutkan dengan penjelasan cara pengisian kuesioner. Hasil kuesioner kemudian dihitung jumlah skornya dan digolongkan sesuai dengan derajat ketentuan yang berlaku, yaitu insomnia ringan, sedang dan berat.

Pengolahan data yang dilakukan menggunakan program SPSS. Adapun analisis yang dilakukan meliputi analisis univariat yaitu usia, jenis stroke dan riwayat insomnia. Uji Anova digunakan untuk analisis data perbedaan rerata usia terhadap derajat insomnia. Uji Chi square digunakan untuk analisis data perbedaan jenis stroke terhadap derajat insomnia 


\section{HASIL}

Berdasarkan hasil analisis data rerata usia menurut derajat insomnia yang dilakukan dengan menggunakan SPSS didapatkan hasil sebagai berikut:

Tabel 1.1 Distribusi rata-rata Usia menurut derajat insomnia

\begin{tabular}{|c|c|c|c|c|}
\hline Variabel & Mean & SD & $95 \% \mathrm{CI}$ & $\begin{array}{l}\mathrm{p} \\
\text { Value }\end{array}$ \\
\hline \multirow{2}{*}{$\begin{array}{l}\text { Derajat } \\
\text { insomnia } \\
\text { Ringan }\end{array}$} & & & & \multirow{4}{*}{0,003} \\
\hline & 47,7 & 8,78 & $\begin{array}{l}42,47- \\
53,07\end{array}$ & \\
\hline Sedang & 55,4 & 4,69 & $\begin{array}{l}52,04- \\
58,76\end{array}$ & \\
\hline Berat & 58,8 & 8,49 & $\begin{array}{l}54,10- \\
63,50\end{array}$ & \\
\hline
\end{tabular}

Rerata usia pasien stroke yang mengalami insomnia ringan adalah 47,7 tahun dengan standar deviasi 8,78. Rerata usia pasien stroke yang mengalami insomnia sedang adalah 55,4 dengan standar deviasi 4,69. Hasil uji statistik didapatkan nilai 0,003, berarti pada alpha 5\% dapat disimpulkan ada perbedaan rerata usia pada derajat insomnia.

Tabel 1.2 Distribusi Riwayat Insomnia Menurut Derajat Insomnia (uji kolmogorov smirnov)

\begin{tabular}{|c|c|c|c|c|c|c|c|}
\hline & \multicolumn{6}{|c|}{ Insomnia } & \multirow[t]{3}{*}{ p } \\
\hline & \multicolumn{2}{|c|}{ Ringan } & \multicolumn{2}{|c|}{ Sedang } & \multicolumn{2}{|c|}{ Berat } & \\
\hline & $\mathrm{n}$ & $\%$ & $\mathrm{n}$ & $\%$ & $\mathrm{n}$ & $\%$ & \\
\hline \multirow{2}{*}{$\begin{array}{l}\text { Tidak } \\
\text { pernah }\end{array}$} & 1 & 34 , & 1 & 26 , & 2 & 5,3 & \multirow{6}{*}{$\begin{array}{c}1,00 \\
0\end{array}$} \\
\hline & 3 & 2 & 0 & 3 & & & \\
\hline Memiliki & 0 & 0 & 0 & 0 & 1 & 34 , & \\
\hline riwayat & & & & & 3 & 2 & \\
\hline sebelumn & & & & & & & \\
\hline & & & & & & & \\
\hline \multirow{2}{*}{ Total } & 1 & 34 , & 1 & 26 , & 1 & 39 , & \\
\hline & 3 & 2 & 0 & 3 & 5 & 6 & \\
\hline
\end{tabular}

Hasil analisis riwayat insomnia dengan derajat insomnia pada pasien stroke didapatkan 13 orang tidak memiliki riwayat insomnia mengalami insomnia ringan, 10 orang insomnia sedang dan 2 orang mengalami insomnia berat. Jumlah pasien stroke yang memiliki riwayat insomnia sebelum stroke mengalami insomnia berat sejumlah 13 orang. Hasil uji statistik didapatkan $\mathrm{p}=1,000$ maka dapat disimpulkan tidak ada perbedaan proporsi kejadian derajat insomnia antara pasien stroke yang memiliki riwayat insomnia sebelum sakit dengan pasien stroke yang tidak memiliki riwayat insomnia.

Tabel 1.3 Distribusi Jenis Stroke Menurut Derajat Insomnia (Pearson Chi Square)

\begin{tabular}{|c|c|c|c|c|c|c|c|}
\hline & \multicolumn{7}{|c|}{ Insomnia } \\
\hline & Rin & & Sed & & $\mathrm{Be}$ & & $p$ \\
\hline & gan & & ang & & rat & & \\
\hline $\begin{array}{l}\text { Jenis } \\
\text { stroke }\end{array}$ & $\mathrm{n}$ & $\%$ & $\mathrm{n}$ & $\%$ & $\mathrm{n}$ & $\%$ & $\begin{array}{c}0,0 \\
00\end{array}$ \\
\hline $\begin{array}{l}\text { Iskemi } \\
\mathrm{k}\end{array}$ & 12 & $\begin{array}{r}31 \\
, 6\end{array}$ & 10 & $\begin{array}{l}26, \\
32\end{array}$ & 1 & 2,6 & \\
\hline $\begin{array}{l}\text { Perdar } \\
\text { ahan }\end{array}$ & 1 & $\begin{array}{l}2, \\
6\end{array}$ & 0 & 0 & 14 & $\begin{array}{l}36 \\
84\end{array}$ & \\
\hline Total & 13 & $\begin{array}{c}34 \\
2\end{array}$ & 10 & $\begin{array}{l}26, \\
32\end{array}$ & 15 & $\begin{array}{l}39, \\
44\end{array}$ & \\
\hline
\end{tabular}

Hasil analisis hubungan jenis stroke dengan derajat insomnia pasien stroke diketahui bahwa pada pasien stroke jenis iskemik didapatkan 12 orang mengalami insomnia ringan, 10 orang mengalami insomnia sedang dan satu orang mengalami insomnia berat. Pasien stroke perdarahan diketahui satu orang mengalami insomnia ringan dan 14 orang mengalami insomnia berat. Hasil uji statistik diperoleh nilai $\mathrm{p}=0,000$ maka dapat disimpulkan ada perbedaan proporsi kejadian derajat insomnia antara pasien stroke iskemik dan perdarahan.

\section{PEMBAHASAN}

Berdasarkan hasil uji analisis rerata usia menurut derajat insomnia didapatkan adanya perbedaan rerata usia pada derajat insomnia. Rerata usia pasien stroke yang mengalami insomnia ringan adalah 47,7 tahun sedangkan rerata usia pasien yang mengalami insomnia sedang adalah 55,4. Hasil ini dapat dijelaskan bahwa seiring dengan peningkatan usia seseorang akan meningkatkan risiko terjadinya masalah gangguan tidur. Delaune \& Ladner (2013) menjelaskan beberapa faktor yang mempengaruhi kuantitas dan kualitas tidur meliputi tahap tumbuh kembang (usia), kondisi sehat sakit, kecemasan, lingkungan, gaya hidup, diet, obat-obatan dan substansi lainnya dan norma budaya.

Pada kelompok insomnia ringan rerata usia lebih muda dibandingkan dengan kelompok insomnia sedang. Oleh karena itu, dapat disimpulkan bahwa hasil penelitian ini sesuai dengan konsep teori usia dalam 
kaitannya dengan gangguan tidur yang terjadi terutama pada peningkatan usia.

Kesimpulan hasil analisis riwayat insomnia dengan derajat insomnia didapatkan pada pasien stroke adalah tidak ada perbedaan proporsi kejadian derajat insomnia antara pasien stroke yang memiliki riwayat insomnia sebelum sakit dengan pasien stroke yang tidak memiliki riwayat insomnia $(\mathrm{p}=1,000)$. Dari 38 orang responden didapatkan 13 orang tidak memiliki riwayat insomnia mengalami insomnia ringan, 10 orang insomnia sedang dan 2 orang mengalami insomnia berat. Hasil penelitian ini sesuai dengan konsep teori yang mengatakan bahwa perubahan atau gangguan tidur yang terjadi pada pasien stroke berhubungan dengan area lesi di otak. Hal ini berhubungan dengan kerusakan fungsi bagian otak tertentu akan mempengaruhi regulasi tidur (batang otak, hipotalamus dan talamus).

Michael K (2009) menyatakan hasil pemeriksaan EEG menunjukkan adanya bentuk abnormal gelombang tidur yaitu penurunan signifikan tidur gelombang lambat (slow wave sleep) dan rapid eye movement (REM). Jenis gangguan tidur gelombang lambat yang sering terjadi berupa insomnia, kantuk berlebihan dan hipersomnia.

Kesimpulan hasil analisis jenis stroke dengan derajat insomnia pasien stroke didapatkan diketahui ada perbedaan proporsi kejadian derajat insomnia antara pasien stroke iskemik dan perdarahan $(\mathrm{p}=0,000)$. Dari keseluruhan responden diketahui bahwa pasien stroke jenis iskemik didapatkan 12 orang mengalami insomnia ringan, 10 orang mengalami insomnia sedang dan satu orang mengalami insomnia berat. Pasien stroke perdarahan diketahui satu orang mengalami insomnia ringan dan 14 orang mengalami insomnia berat.

Secara konsep teori belum diketahui secara pasti kaitan dengan jenis stroke dengan derajat insomnia. Namun kerusakan area otak tertentu yang berkaitan dengan fungsi tidur akan menimbulkan dampak gangguan tidur pada pasien stroke. Hal ini adanya hubungan timbal balik antara tiga sistem saraf menghasilkan siklus tidur bangun dan tahapan tidur (Sheerwood, 2009). Tiga sistem saraf yang dimaksud adalah:

1. bagian sistem aktivasi retikular/reticular activating system yang berasal dari batang otak (sistem keterjagaan),
2. hipotalamus (pusat tidur gelombang lambat/ NREM)

3. batang otak (pusat tidur paradoksal)

Snell (2014) menyatakan bahwa tidur merupakan akibat penurunan aktivasi formasio retikularis. Anatomi formasio retikularis dibentuk dari neuron-neuron yang saling berhubungan membentuk suatu anyaman di batang otak dan masuk ke talamus. Jaringan ini menerima dan mengintegrasikan semua masukan sinaptik sensorik yang datang kemudian serat asenden yang berasal dari formasio retikularis membawa sinyal ke atas untuk membangunkan dan mengaktifkan korteks serebri. Serat-serat ini membentuk sistem pengaktif retrikular (reticular activating system/ RAS) dan berperan dalam mengontrol derajat kewaspadaan korteks dan mengarahkan perhatian sedangkan serat desenden dari korteks dapat mengaktifkan RAS.

\section{SIMPULAN}

Penelitian ini mengidentifikasi beberapa hasil yaitu Ada perbedaan yang signifikan antara rerata usia antara derajat insomnia ringan dan sedang. Hal ini dapat diketahui dari hasil rerata usia pasien stroke yang mengalami insomnia ringan adalah 47,7 tahun dengan standar deviasi 8,78 sedangkan rerata usia pasien stroke yang mengalami insomnia sedang adalah 55,4 dengan standar deviasi 4,69. Secara konsep teori dapat dihubungkan dengan gangguan tidur dapat terjadi seiring peningkatan usia. Dengan demikian terdapat keselarasan antara hasil penelitian (insomnia sedang pada rerata usia 55,4) dengan konsep gangguan tidur yang terjadi seiring dengan peningkatan usia.

Tidak adanya perbedaan proporsi kejadian derajat insomnia antara pasien stroke yang memiliki riwayat insomnia sebelum sakit dengan pasien stroke yang tidak memiliki riwayat insomnia. Kondisi ini memberikan gambaran bahwa seseorang yang memiliki riwayat insomnia sebelum sakit stroke tidak memberikan dampak tehadap kejadian insomnia pasca stroke. Dengan kata lain, seseorang yang tidak memiliki riwayat insomnia sebelum sakit stroke belum tentu bebas dari insomnia pasca stroke. Kondisi ini dapat dijelaskan dengan penyebab insomnia dapat bervariasi, yaitu berkaitan dengan kondisi fisiologis seseorang yang mengalami dampak 
langsung dari stroke atau factor eksternal seperti lingkungan.

Adanya perbedaan proporsi kejadian derajat insomnia antara pasien stroke iskemik dan perdarahan. Hal ini diketahui berdasarkan jumlah responden pasien stroke iskemik, 12 orang mengalami insomnia ringan, 10 orang mengalami insomnia sedang dan satu orang mengalami insomnia berat. Pasien stroke perdarahan diketahui satu orang mengalami insomnia ringan dan 14 orang mengalami insomnia berat. Kondisi patologis yang terjadi pada pasien stroke dapat mempengaruhi kondisi klinis termasuk keluhan insomnia pasca stroke. Dengan demikian hasil penelitian ini sesuai dengan konsep stroke terhadap derajat insomnia.

\section{SARAN}

Hasil penelitian ini dapat menjadi satu dasar untuk membuat suatu perencanaan penelitian lanjutan yang dapat memberikan maanfaat bagi perkembang ilmu keperawatan khususnya dalam upaya pemulihan pasien stroke.

Bagi masyarakat, perlu dilakukan upaya yang dapat membantu meminimalkan masalah insomnia pada pasien stroke sehingga dapat mengoptimalkan masa pemulihan dan meminimalkan dampak masalah insomnia pada pasien stroke. upaya yang dilakukan dapat dengan mendeteksi dan mengenal masalah insomnia secara dini sehingga dapat melakukan upaya penanganan insomnia dan meningkatkan kualitas tidur pasien stroke.

\section{UCAPAN TERIMA KASIH}

Penelitian ini tidak dapat terlaksana dengan baik tanpa kerjasama dan bantuan banyak pihak, baik secara langasung maupun tidak langsung. Oleh karena itu, peneliti mengucapkan terima kasih pada semua pihak yang telah banyak membantu dari awal proses penelitian sampai dengan selesainya tahap

\section{DAFTAR PUSTAKA}

Barcan, R. (2014). Aromatherapy Oils. Commodities, Materials, Essences. Cultural Studies Review, 20(September), 141-171. http://dx.doi.org/10.51310/csr.v20i2.3615
Bader \& Littlejohns. (2004). AANN Core Curriculum for Neuroscience Nursing Fourth Edition.Saunders: St. Louis.

Biçer, S. (2015). The Effect of Aromatherapy Massage Applied to Facial Area upon Headache Severity among Patients who Suffered from Headache During Hemodialysis, International Journal of Caring Science, 8(3), 722-729.

Black\& Hawk .(2014). Keperawatan Medikal Bedah: Manajemen Klinis untuk Hasil yang Diharapkan. Elseiver: Singapura.

Bulechek et al. (2013). Nursing Interventions Classification Sixth Edition.Elseiver Saunders: St. Louis.

Cavalcanti, P. R. A., Campos, T. F., \& Araüjo, J. F. (2013). Circadian and homeostatic changes of sleep-wake and quality of life in stroke: Implications for neurorehabilitation. NeuroRehabilitation, 32(2), 337-343. http://doi.org/10.3233/NRE-130853

Cho, M., Min, E. S., Hur, M., \& Lee, M. S. (2013). Effects of Aromatherapy on the Anxiety, Vital Signs, and Sleep Quality of Percutaneous Coronary Intervention Patients in Intensive Care Units, 2013.

Crossman A.R \& Neary, D. (2015). Neuroanatomy. Elsevier: Philadelphia

Das, S., Deepa, O. V., Pradhan, J., \& Kumari, S. (2015). Factors of sleep Disturbances among Hospitalized Patients, Jeopardizing the Prognosis. Asian Journal of Nursing Education and Research, 5(2), 302. http://doi.org/10.5958/23492996.2015.00061.0

Daroff, R. B. (1991). The International Classification of Sleep Disorders: Diagnostic and Coding Manual. Neurology. http://doi.org/10.1212/WNL.41.1.160

Delaune, Sue. D \& Ladner, Patricia.k. (2011). Fundamental of Nursing. Standars \& Practice. Fourth Edition. Delmar: New 
York.

Dharma, Kusuma Kelana.(2011). Metodelogi Penelitian Keperawatan. CV Trans Info Media: Jakarta.

Fitzgerald, $\mathrm{M}$ et al (2012). Clinical Neuroanatomy and Neuroscience. Elsevier Saunders: St. Louis.

Guyton, Arthur, C \& Hall, Jhon E. (2014).Guyton dan Hall Buku Ajar Fisiologi Kedokteran Edisi Keduabelas. Elsevier: Singapore

Herdman, T.H. (2012). NANDA International Nursing Diagnoses: Definitions \& Classification 2012-2014. WileyBlackwell: Iowa

Hickey, J.V. (2003). The Clinical Practice of Neurological and Neurosurgical Nursing Fifth Edition. Lippincot William \& Wilkins: Philadelphia

Kozier \& Erb's. (2008). Fundamental of Nursing. Conceps, Process, \& Practice. $8^{\text {th }} \quad$ Edition. January, 3, 2016. http://www.Prenhall.co./berman

Lillehei, A. S., \& Halcon, L. L. (2014). A Systematic Review of the Effect of Inhaled Essential Oils on Sleep. Journal of Alternative and Complementary Medicine (New York, N.Y.), O0(0), 1-11. http://doi.org/10.1089/acm.2013.0311

Lindquist et al (2014) Complementary \& Alternative Therapies in Nursing Seventh Edition. Springer Publishing Company: New York.

Lytle, Jamie., Mwatha, Catherine., \& Davis, Karen K (2014). Effect of Lavender Aromatherapy On Vital Signs And Perceived Quality Of Sleep In The Intermediate Care Unit: A Pilot Study. American Association of Critical Care Nurse, $\quad 23$ http://.doi.org/10.4037/ajcc2014958

Michael, K. (2009). Fatigue and Sleep Disturbances after Stroke. Post-Stroke Complication and Their Treatment, (4),
469-481.

Moeini , Khadibi m, Bekradi R, Mahmoudian SA, Nazari F. Effect of Aromatherapy on The Quality of Sleep in Ischemic Disease Patients Hospitalized in Intensive Care Unit of Hospitals of The Isfahan University of Medical Sciences, Iran J Nurs Midwifery Res. 2010;15 (4):234-239.

Manconi, M. et al. (2014). Longitudinal Polysomnographic Assessment from Acute to Subacute Phase in Infratentorial versus Supratentorial Stroke, 85-93. http://doi.org/10.1159/000356323

Moorhead et al. (2013). Nursing Outcomes Classification Fifth Edition. Elseiver: St. Louis

Morin, C. M., Belleville, G., Bélanger, L., \& Ivers, H. (2011). The Insomnia Severity Index: psychometric indicators to detect insomnia cases and evaluate treatment response. Sleep, 34(5), 601-608. http://doi.org/10.1111/j.13652648.2010.05394.x

Morin CM., LeBlanc M., Belanger L., Ivers H., Merette, C., \& Savard J. (2011). Prevalence of Insomnia and It's Treatment in Canada. Can J Psychiatry, 56 (9), 540548.

Pasic, Z., Smajlovic, D., Dostovic, Z., Kojic, B., \& Selmanovic, S. (2011). Incidence and types of sleep disorders in patients with stroke. Medicinski Arhiv, 65(4), 225227.

http://doi.org/10.5455/medarh.2011.65.22 5-227

Snell, Richard S. (2014). Neuroanatomi Klinik Edisi Tujuh. EGC: Jakarta.

Sherwood, Lauralee.(2009). Fisiologi Manusia Dari Sel Ke Sistem. EGC: Jakarta

Dahlan, S. (2014). Langkah Langkah Membuat Proposal Penelitian Bidang Kedokteran dan Kesehatan.CV Sagung Seto: Jakarta 
Sterr, A., Herron, K., Dijk, D.-J., \& Ellis, J. (2008). Time to wake-up: sleep problems and daytime sleepiness in long-term stroke survivors. Brain Injury: [BI], 22(August 2015), 575-579. http://doi.org/10.1080/026990508021897 27

Swanenghyun,G., Astuti \& Ghofir, A. (2015). Validitas Dan Reliabilitas Alat Ukur Insomnia Severity Indeks Versi Indonesia (ISI-INA) Pada Remaja Jalanan Di Yogyakarta. Universita Gajah Mada, Yogyakarta

Taavoni, S., Darsareh, F., Joolaee, S., \& Haghani, H. (2013). The effect of aromatherapy massage on the psychological symptoms of postmenopausal Iranian women \&. Complementary Therapies in Medicine, 21(3), 158-163. http://doi.org/10.1016/j.ctim.2013.03.007

Terzoudi, A., et al. (2009). Sleep Architecture in Stroke and, 16-22. http://doi.org/10.1159/000165344

Teng, L., Tan, H., Lee, L. H., Yin, W. F., Chan, C. K., Kadir, H. A., ... Goh, B. H. (2015). Traditional Uses, Phytochemistry, and Bioactivities of Cananga odorata ( YlangYlang ), Evidence-Based Complementary and Alternative Medicine, 2015. http://dx.doi.org/10.1155/2015/896314

Thibodeu, Patton. (2013). Anthony's Textbook of Anatomy \& Physiology $20^{\text {th }}$ Edition. Elsevier: St. Louis

Woodward, S \& Mestecky, A. (2011). Neuroscience Nursing Evidence-Based Practice. Wiley-Blackwell:United Kingdom 